\title{
A SURVEY OF TEACHERS' OPINIONS ABOUT IMPLEMENTING REALISTIC MATHEMATICS EDUCATION IN TEACHING THE TOPICS OF THE ELLIPSE EQUATION
}

\author{
Lam Truong Khanh ${ }^{1}$, \\ Duong Huu Tong'i, \\ Lu Kim Ngan ${ }^{3}$ \\ ${ }^{1}$ Doan Van To High School, \\ Soc Trang Province, \\ Vietnam \\ ${ }^{2}$ Can Tho University, \\ Can Tho City, \\ Vietnam \\ ${ }^{3}$ Master Student, \\ Can Tho University, \\ Can Tho City, \\ Vietnam
}

\begin{abstract}
:
Realistic Mathematics Education (RME) is an instructional theory that has been implemented in many countries around the world to link mathematics to real-world situations. The effectiveness of implementing RME in mathematics education is highly dependent on the role of teachers. This study was conducted with 64 high school teachers to survey their understanding and perspectives on RME and the status of RME implementation in teaching the topics of ellipse equation. Through qualitative analyzing the survey results, the study found that teachers are interested in RME, although the percentage of teachers formally trained in this theory was not high. Besides, the survey shows that it is necessary to help teachers overcome difficulties and improve the frequency and effectiveness of RME application in teaching mathematics.
\end{abstract}

Keywords: ellipse equation, realistic mathematics education, teachers' perspectives

\section{Introduction}

The history of mathematics proves that different fields of mathematics were formed and developed due to the demands of real life. On the other hand, mathematics has several applications in real life, such as tools to study other subjects and sciences, contributing to

i Correspondence: email dhtong@ctu.edu.vn 
developing students' competencies and forming knowledge background for students to deal with daily life problems.

Realistic Mathematics Education (RME) is a domain-specific instruction theory for mathematics, which has been developed in the Netherlands (Van den Heuvel-Panhuizen and Drijers, 2014). Van den Heuvel-Panhuizen (2003) uses realistic contexts to determine characteristics of this approach to mathematics education. In RME, students should learn mathematics by developing and applying mathematical concepts and tools in real-world problem situations (Van den Heuvel-Panhuizen, 2003). According to Gravemeijer and Doorman (1999), context problems are defined as problems in which the problem situation is experientially real to the student. These problems are intended for supporting a reinvention process that enables students to come to grips with formal mathematics in RME (Gravemeijer \& Doorman, 1999).

The characteristics of RME are described in the study of Clements and Sanama (2013) as the application of meaningful contexts, the development of a model which lets the transformation happen from contextual to formal mathematics, the recreation of mathematics concepts by the students, the interaction between students and teacher, and the perception of mathematics as an integrated subject (Clements \& Sanama, 2013).

According to Gravemeijer (1997), RME has three key principles: guided reinvention, didactical phenomenology, and self-developed model (Gravemeijer 1997; as cited in Sumirattana et al., 2017). The first principle means students should have the chance to experience a process similar to how mathematics was invented. Besides, didactical phenomenology leads to the process of the vertical mathematization of students. A self-developed model developed by the students can bridge the gap between informal knowledge and formal mathematics (Freudental, 1983; Gravemeijer 1997; as cited in Sumirattana et al., 2017).

The process of teaching with RME in the study of Deniz (2015) can be summed up as: The teacher gives students a visual of a real-life problem; each student can give their opinion relating to the problem. This problem can attract students' attention and encourage them to apply mathematical skills because the teacher asks questions to explore the relationship between the factors in the problem. Also, the questions often have the form of comparison, cause-effect, yes/no, why, or questions about the influence on one factor when other factors change. In particular, the teacher changes the factors in the problem, asks probing questions or allows students to discuss the relationship between the factors and solve the problem. After answering the questions, students begin the process of vertical mathematization. Teachers can assign exercises with questions related to real situations and the content of this knowledge to prevent interruptions in students' cognitive processes.

A slew of studies has demonstrated the advantages of incorporating RME into secondary mathematics education. The authors Drijvers et al. (2019) conclude that the application of RME in mathematics has positive effects on students' mathematical thinking, modeling and problem-solving abilities (Drijvers et al., 2019). Besides, Laurens et al. (2018) find out that RME also influences students' attitudes, learning interests, or 
other variables related to mathematics learning (Laurens et al., 2018). In other words, the connection of mathematics with real-life and human activities is an effective way to improve students' interest in learning mathematics (Gravermeijer, 1994).

Due to various characteristics and principles of RME and its importance, it is essential to determine how teachers apply RME in teaching. According to Sumirattana et al. (2017), teachers play an important role in empowering students' mathematical experience to apply mathematics to their real-life (Sumirattana et al., 2017). With the role of a facilitator, teachers are the ones who create a learning environment that supports learners (Wahyudi et al., 2017).

On the other hand, teachers face some challenges when attempting to implement RME in the mathematics classroom. Both experienced teachers and prospective teachers face some obstacles relating to teachers' understanding mathematics teaching materials, teachers' familiarity with real-world mathematical problems and the usage of mathematical teaching media/visual aids, teachers' mastery in various approaches of mathematics learning, teachers' skill in arranging lesson plans and in the simulation of mathematics learning (Wahyudi et al., 2017). Additionally, students' difficulties in learning RME are also considered as challenges to teachers. According to Meika et al. (2018), students commit errors in simplifying the problem; errors in making mathematical models (horizontal mathematization); errors in finishing mathematical model (vertical mathematization); and errors in interpretation as well validation (Meika et al., 2018).

The ellipse is a geometric shape that is extremely common in physics, astronomy, and engineering. For instance, the orbit planets in the solar system are roughly an ellipse with the Sun as a focus. The Moon's orbit revolves around the planet, and so do all other binary systems. Ellipses often describe the shapes of planets and stars. The ellipse equations in Geometry 10 have many real-world applications, but the textbook only introduces mathematical knowledge without mentioning its association with real life. In recent years, the national exam in Mathematics has included several questions with realworld problems. Therefore, the application of RME in teaching the ellipse equation is an effective method for teachers to exploit the practical applications of this knowledge, improve teaching efficiency, and impulse students' learning interest and ability to resolve real-world problems.

\section{Research Objectives}

The study was carried out to survey the perspectives and status of applying RME in teaching mathematics, especially for the ellipse equation of high school teachers, including:

1) Teachers' understanding of RME and the application of RME in teaching mathematics.

2) The frequency of applying RME in teaching mathematics, especially in teaching the topic of ellipse equations. 
3) Difficulties and challenges that teachers encountered when teaching mathematics with RME orientation.

4) Teachers' using of different real-world problems in teaching the topic of ellipse equations.

\section{Research Methodology}

\subsection{Participants}

It was conducted with 64 teachers who were responsible for teaching mathematics in high schools in Vietnam. It includes 15 high schools in Soc Trang City, Hau Giang Province, Can Tho City, Vinh Long City, Tien Giang Province and Ben Tre City.

\subsection{Procedure and Instrument}

\subsubsection{Procedure}

The research process is depicted in the diagram below (see Figure 1):
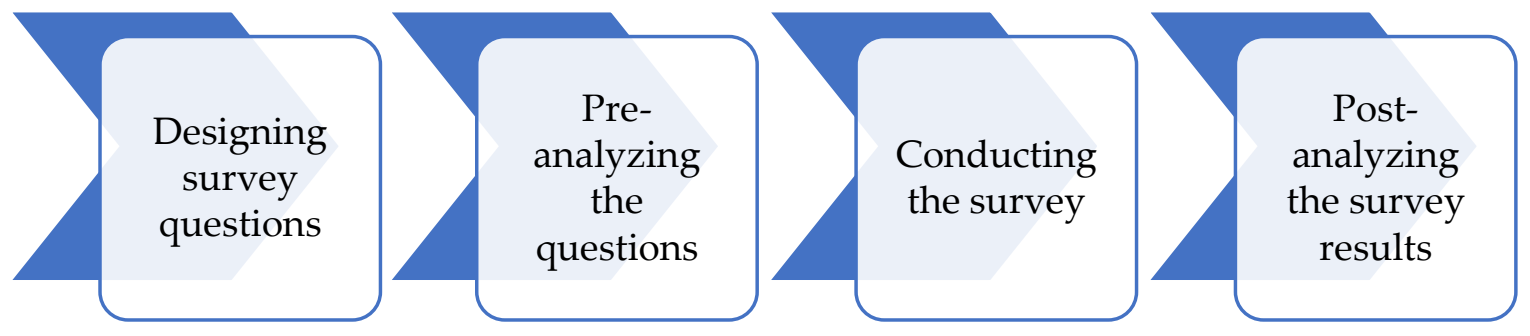

Figure 1: The process of research

\subsubsection{Instrument}

The survey questionnaire includes seven questions. It was conducted via Google Forms, and the results were described by charts made by Excel software. From the above perspectives of RME, the study proposes a model of teaching process with RME orientation, including the following six steps in Figure 2: 
Teacher introduces a real-world problem related to the knowledge

Teacher guides students to interact, discuss, compare their opinions and choose a solution to the problem

Students present their solutions and draw conclusions about the problem

The teacher concludes about the problem and presents the knowledge

Students solve new problems related to the knowledge

Teacher consolidates students' knowledge

Figure 2: The 6-step model of teaching

Step 1: Teacher designs or collects real-world problems related to the knowledge, then sets the requirements to be implemented. Through exploring and solving problems, students will have a clearer view of the knowledge and the relationship between mathematics and real life.

Step 2: After giving the real-world problem, the teacher can divide the class into small groups. Students will think and come up with their solutions. Each group will discuss and choose the appropriate solution. Then, the groups will discuss all the proposed solutions and choose optimal solutions.

Step 3: In the above steps, students have selected some optimal solutions. Students have to present in detail the reason for choosing the option and give arguments to prove that their solution is appropriate.

Step 4: After students discussing and presenting the solutions, the teacher evaluates the solutions and concludes the problem. In this step, the teacher can give the most optimal solution or state which solutions are feasible. After solving the problems, the teacher presents the knowledge.

Step 5: After students are equipped with the necessary knowledge, teachers can give new relevant real-world problems to apply their newly learned knowledge to cope with the problems.

Step 6: Teacher reinforces lesson knowledge for students in different ways, such as multiple-choice tests, maps and tables, a system of questions and exercises, games or by allowing students to summarize their knowledge. While consolidating the lesson, depending on the content, the level to be achieved in terms of teaching objectives, implementation time and target of students, appropriate measures can be selected. 


\section{Results and Discussion}

Question 1: Have you been trained in teaching mathematics with RME orientation?

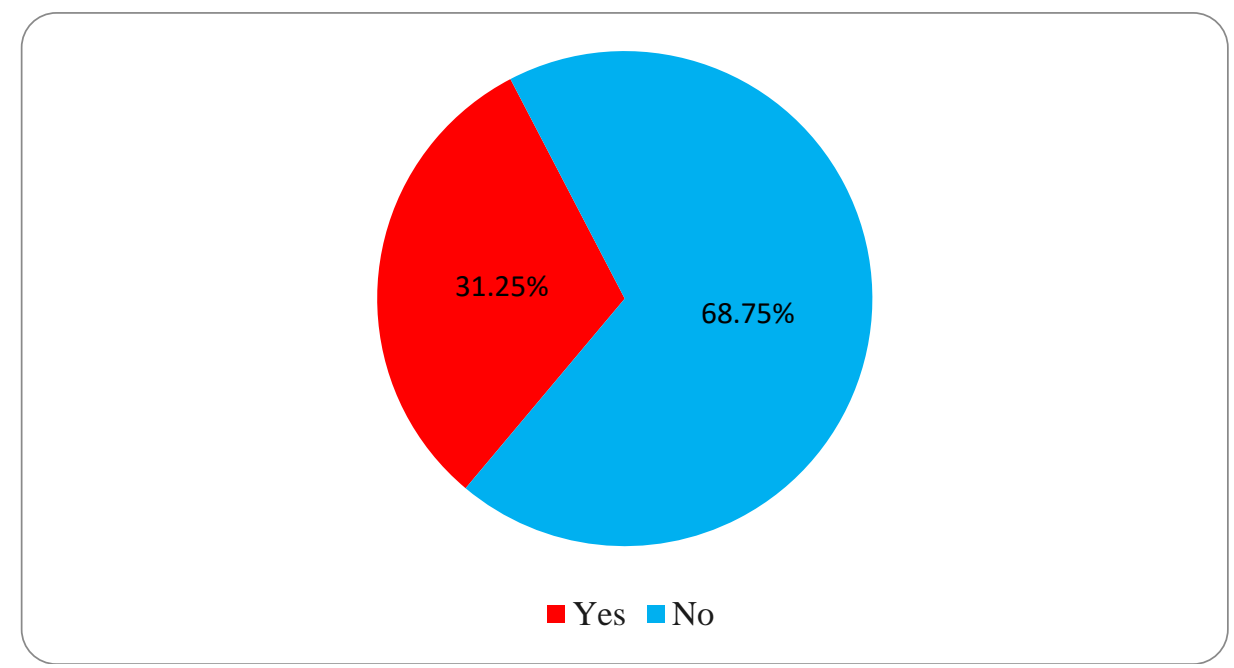

Figure 3: The statistics of answering question 1

The objective of question 1 was to find out the level of teachers' approach to RME. The statistical survey results in Figure 3 show that up to $68.75 \%$ of the total teachers participating in the survey have not been trained in teaching with RME orientation. Figure 3 also shows that $31.25 \%$ have participated in training on RME. This outcome indicates that most teachers have to research by themselves to get more information about RME. Based on these results, we recommend that teacher training schools complement the topic of RME into training programs. The Departments of Education and Training should train teachers, including this content in the training course for high school teachers and general education administrators.

Question 2: Please select the following contents and arrange them in the sequence of the teaching process applying RME in Mathematics:

1) The teacher introduces a real-world problem related to the knowledge

2) The teacher guides students to interact, discuss, compare their opinions and choose a solution to the problem.

3) Students present their solutions and conclude the problem.

4) The teacher concludes about the problem and presents the knowledge

5) Students solve new problems related to the knowledge

6) Teacher consolidates students' knowledge. 


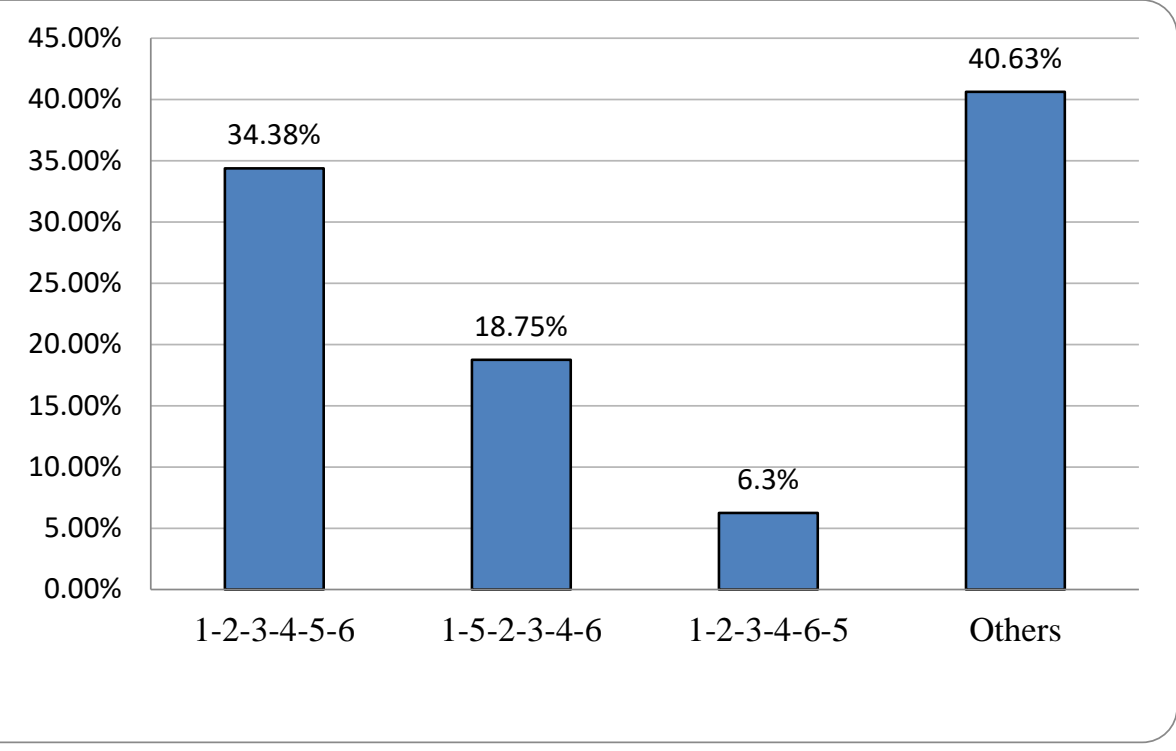

Figure 4: The statistics of answering question 2

The objective of question 2 was to introduce the teaching process of applying RME in teaching mathematics. Figure 4 indicates that $34.38 \%$ of teachers arranged similarly to Figure 2 of the proposed model. Next, 18.75\% of teachers will let students resolve the problem immediately after giving the real-world problem. This data reflects an aspect of teaching mathematics. The current teaching is focused on solving exercises corresponding to the newly learned knowledge. In addition, $6.3 \%$ said that teachers need to organize for students to address new real-world problems related to the lesson content and reinforce them.

Notably, the chart in Figure 4 also shows that up to $40.63 \%$ could not arrange an appropriate process. This result is completely consistent with question 1, with $68.75 \%$ saying that teachers have not been trained on RME. However, the above results show that RME's importance and teachers' concern about RME is gradually improving.

Question 3: In what situations of teaching mathematics do you think RME can be applied? (can choose more than one answer) 


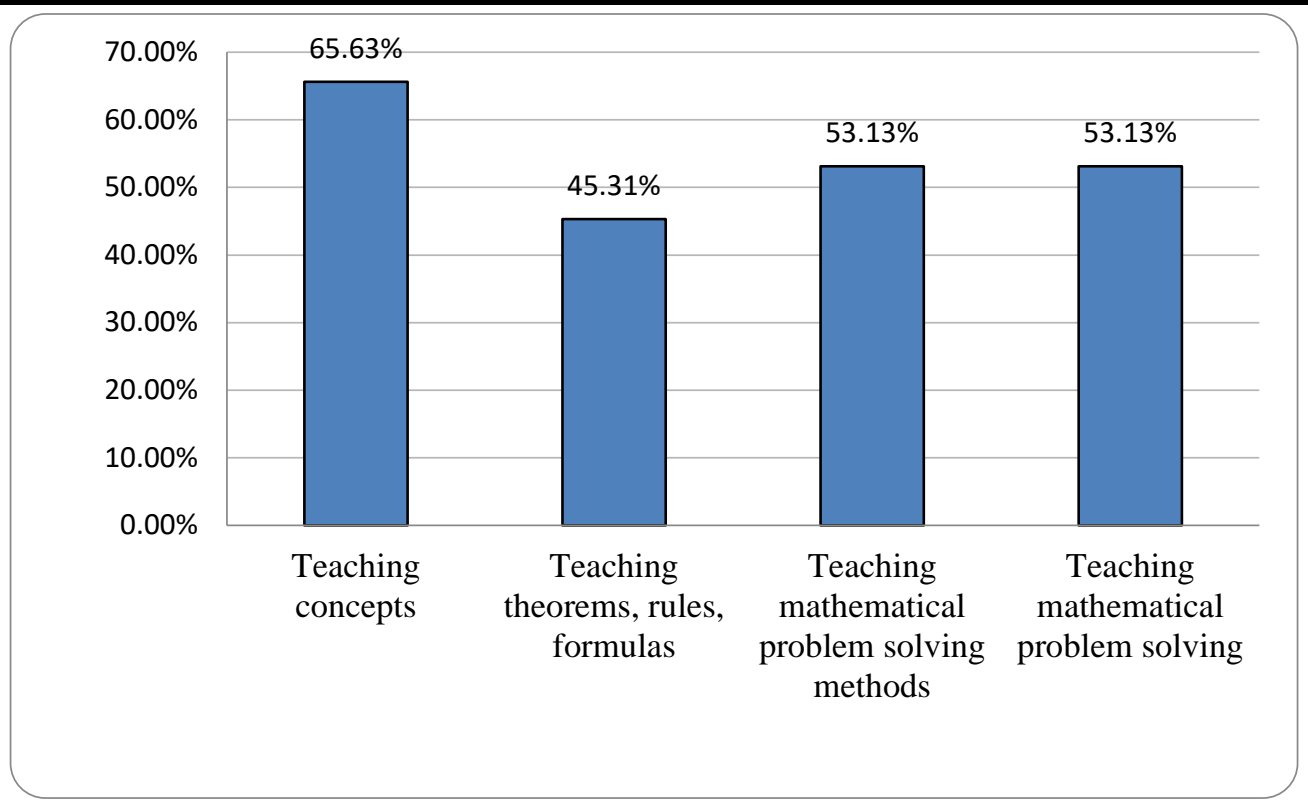

Figure 5: The statistics of answering question 3

Figure 5 shows the applicability of RME in different teaching situations. As a result, the majority of teachers participating in the survey think that it can be applied to teaching concepts $65.63 \%$; there is no difference in the percentages of the two situations of teaching mathematical problem-solving methods and teaching mathematical problem solving with $53.13 \%$; teaching theorems, rules, and formulas were chosen by $45.31 \%$ of teachers. This result shows that in all situations, RME can be applied. The result in each option is at a fairly high rate.

Question 4: How often do you apply RME in teaching mathematics?

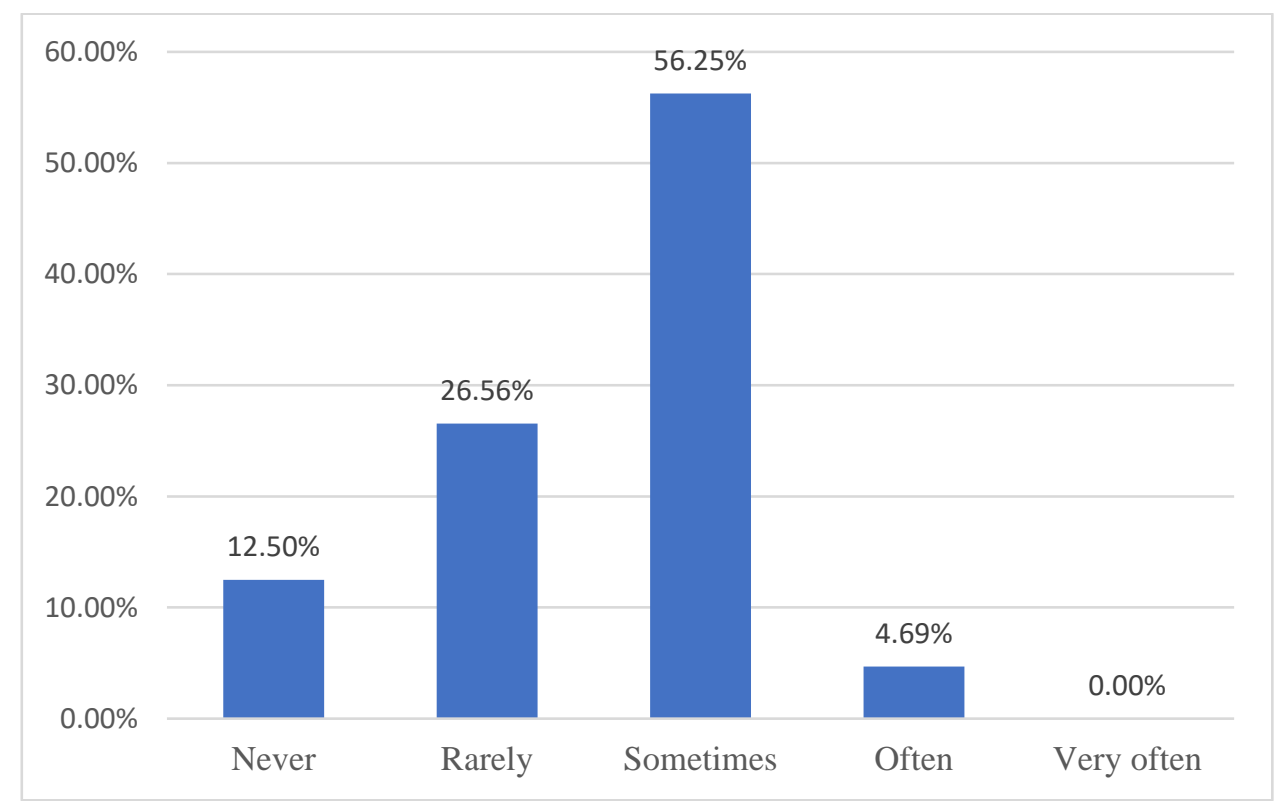

Figure 6: The statistics of answering question 4 
The results of assessing the frequency of RME application through the chart in Figure 6 show that: A very small percentage (4.69\%) of teachers said that they often use RME; up to $82.81 \%$ applied it occasionally, $56.25 \%$ sometimes and $26.56 \%$ rarely. Even up to $12.50 \%$ of teachers said that they have never used it. This result is somewhat opposite to question 3 (Teachers find it can be applied in all teaching situations); the reasons will be analyzed more clearly in question 6.

Question 5: According to you, what are the benefits of teaching mathematics using the RME model? (can choose more than one answer)

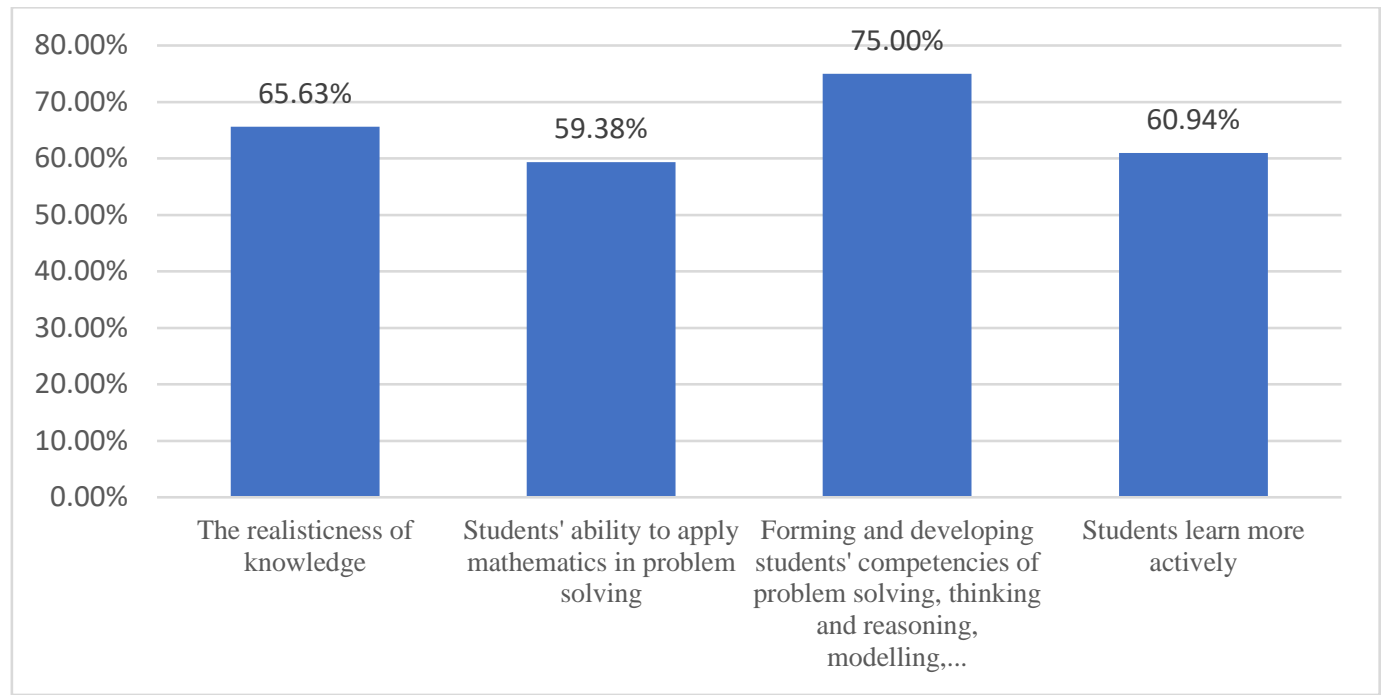

Figure 7: The statistics of answering question 5

The survey results in Figure 7 reveal that teachers all appreciate the benefits of teaching mathematics with RME orientation. The highest rating (75\%) of teachers agreed with the ability to form and develop problem-solving; thinking and reasoning; modeling; competencies of students; the rate of realisticness of knowledge is $65.63 \%$; $60.94 \%$ of teachers think that students learn more actively and $59.38 \%$ is the rate of teachers find that RME improves students' ability to apply mathematics in problem-solving. This positive result once again affirms the necessity of applying real-world problems in teaching mathematics.

Question 6: When organizing mathematics teaching with RME orientation, what do you think are the possible difficulties? (can choose more than one answer) 


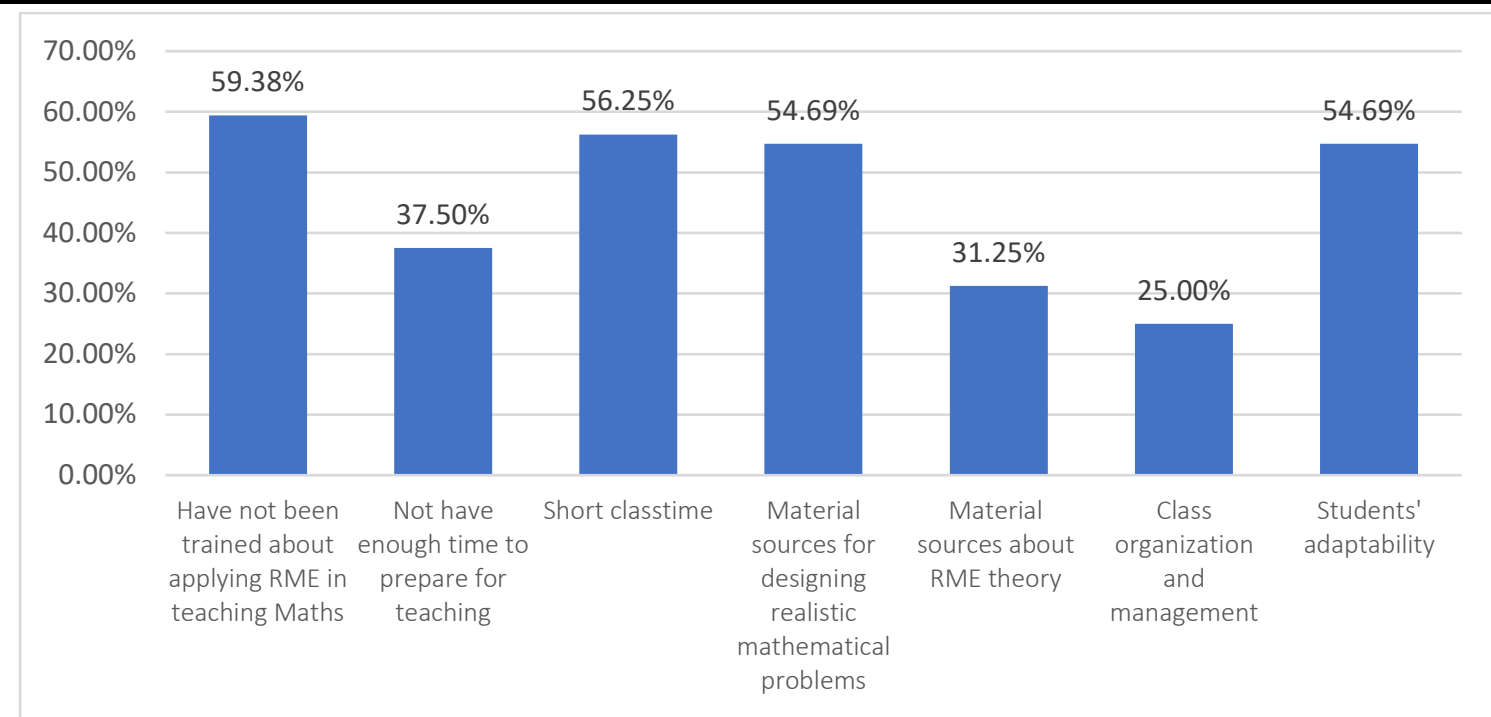

Figure 8: The statistics of answering question 6

It is observed that Figure 8 shows teachers' points of view about different difficulties of applying RME in teaching. They are divided into two groups, specifically: (1) Difficulties encountered by more than $50 \%$ of teachers (mainly due to objective reasons): Not trained in applying RME in teaching mathematics, short classtime, source of materials for designing mathematical problems, and adaptability of students is not high; (2) Difficulties that few teachers encountered (mainly subjective reasons): Not have enough time to prepare for teaching, resources on RME are limited or problems of classroom organization and management.

The findings of this survey suggest that teachers should be more involved in selfstudy and research on RME theory (through the internet, education journals, colleagues); regularly exchange and discuss RME topics in the professional activities of the subject groups at school; and regularly exchange and discuss RME topics in the professional activities of the subject groups at school (adjusting program distribution, organizing teaching and learning, increasing the frequency of application, improving students adaptability... with more real-world problems). Besides, high schools should have solutions such as equipping a computer room to help students practice (for example, in learning the ellipse equation, using software to draw an ellipse on the coordinate plane; observing how the shape changes when the factors in the equation are changed; practicing using software for graphic design related to the ellipse); providing resources and materials for teachers; and providing resources and materials for students and teachers. The above solutions can contribute to improve the teaching environment and help teachers gradually overcome difficulties.

Question 7: In teaching the ellipse equation, did you use similar real-world problems in each situation? 


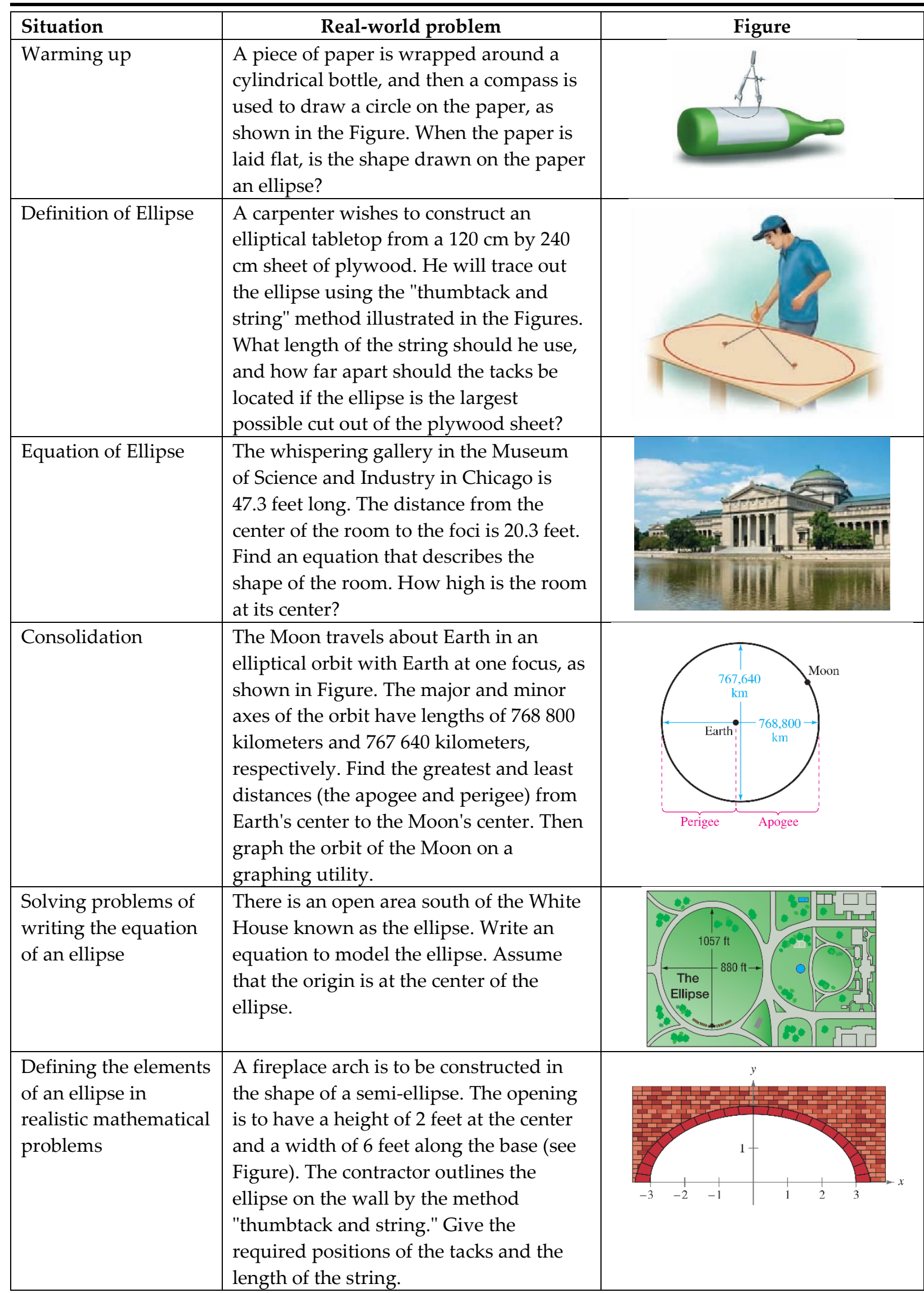




\begin{tabular}{|l|l|}
\hline \hline $\begin{array}{l}\text { Applying, further } \\
\text { exploring }\end{array}$ & $\begin{array}{l}\text { A lithotripter of height } 15 \text { centimeters } \\
\text { and with a diameter of } 18 \text { centimeters is } \\
\text { to be constructed (see the Figure). High- } \\
\text { energy underwater shock waves will be } \\
\text { emitted from the focus } \mathrm{F} \text { that is closest to } \\
\text { the vertex } \mathrm{V} . \\
\text { a. Find the distance from } \mathrm{V} \text { to F. } \\
\text { b. How far from } \mathrm{V} \text { (in the vertical } \\
\text { direction) should a kidney stone be } \\
\text { located? }\end{array}$ \\
\hline
\end{tabular}

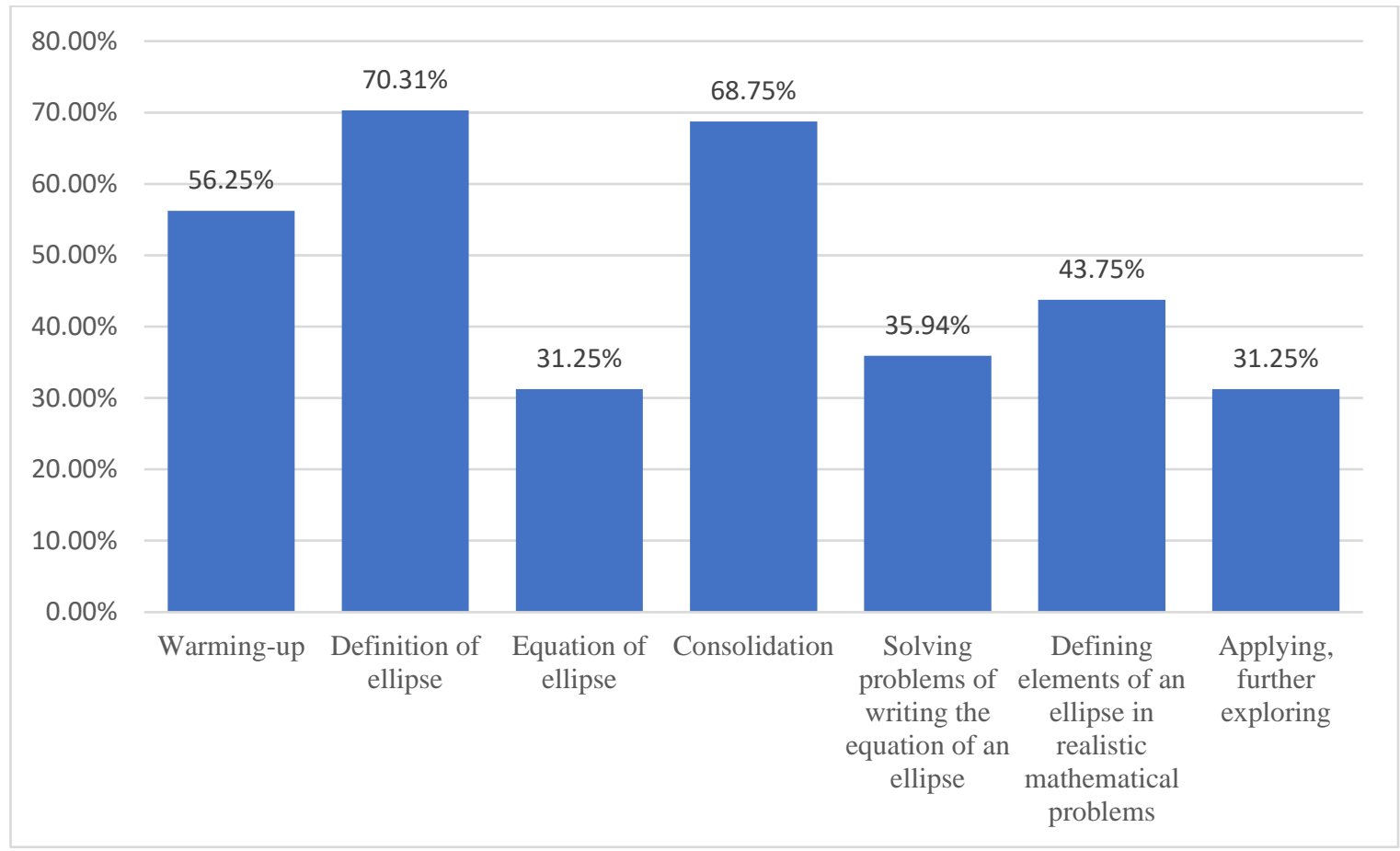

Figure 9: The statistics of answering question 7

The objective of question 7 was to investigate the use of similar real-world problems in teaching the ellipse equation. With the chart in Figure 9, it is easy to see a great difference in real-world problems application in theoretical teaching and practice. Specifically, situations where teachers use similar real-world problems at a high level, are theoretical teaching situations such as warming up, teaching the definition of ellipse and consolidation. In practicing situations, teachers hardly use these similar real-world problems, such as the ellipse equation, determining the elements of an ellipse in the mathematical problem, applying and further exploring. This result reflects reality because most of the time in the lesson, most teachers often focus on training to handle multiple-choice problems for students to match the current trend of testing and assessing. 


\section{Conclusion}

The teacher survey results show that in terms of perspectives towards RME, some teachers have approached RME theory but not the majority. Although the percentage of teachers receiving formal training in RME is quite low, it can be concluded from teachers' responses to the questionnaires that teachers are interested in and actively learn about RME by themselves. Accordingly, the role of teacher training has become increasingly important. Furthermore, it is necessary to include subjects on RME research and application into teacher training curricula. This result is similar to Sumirattana et al. (2017) and Wahyudi et al. (2017). The survey also shows teachers' perspectives on teaching RME, choices of applying RME in situations of teaching, and Similar to the results of previous studies by Wahyudi et al. (2017) and Meika et al. (2018), the majority of teachers (more than 50\%) found obstacles of understanding RME, resources to design real-world problems, time to organize teaching and adaptability of students.

Besides, about the current status of applying RME in teaching Mathematics, most teachers reported the occasional (sometimes) application of RME. When the number of teachers who have received RME training is limited, this is an unavoidable consequence $(31.25 \%)$. At the same time, the difficulties that teachers face are also why teachers choose not to apply RME in teaching regularly. On the other hand, when applying real-world problems in teaching the topic of ellipse equation, most teachers use these problems in activities such as warming up, teaching ellipse definition and consolidation. Meanwhile, in forming formulas, applying knowledge in problemsolving, real-world problems are rarely used. Thus, the application of real-world problems and RME of the teachers participating in the survey promotes the benefits of RME for creating a link between the ellipse and real-life and increasing the learning interest of students. As predicted by the research, this has not fully exploited the significance of RME in training and developing students' problem-solving competency, as it should have. As a result, it is critical to increasing teachers' access to RME resources. At the same time, teachers need to be more active in researching and changing teaching methods to help students apply mathematical knowledge to deal with daily life problems.

In addition to the findings, there are some limitations to the research. With the number of 64 teachers participating in the survey and concentrating in neighboring provinces in the same area, the study results are inevitably local, only reflecting the status of applying RME in teaching mathematics in this area. As a result, new studies can be carried out with larger samples, extending the scope of the survey in terms of geography or school level. Surveys on the status of research and application of RME in teaching mathematics by prospective teachers at teacher training schools also have practical significance. 


\section{Conflict of Interest Statement}

The authors declare no conflicts of interests.

\section{About the Authors}

At Can Tho University in Vietnam, Lam Truong Khanh is studying for a Master's degree in Mathematics Education. For the past 18 years, he has been employed as a Doan Van To High School teacher.

In addition to being an associate professor and a senior lecturer at Can Tho University's School of Education in Can Tho City, Vietnam, Duong Huu Tong also works as a consultant. His expertise has grown over the past 17 years in a variety of fields, including mathematics education, educational evaluation, and curriculum development.

Lu Kim Ngan holds a Master's degree in Mathematical Education from Can Tho University. She has a strong interest in scientific research in the field of education.

\section{References}

Clements, D. H., \& Sarama, J. (2013). Rethinking early mathematics: What is research based curriculum for young children? In L. D. English \& J. T. Mulligan (Eds.), Reconceptualizing early mathematics learning (pp. 121-147). Dordrecht: Springer. https://doi.org/10.1007/978-94-007-6440-8 7

Deniz, O., \& Kabael, T. (2017). Students' mathematization process of the concept of slope within the realistic mathematics education. Hacettepe University Journal of Education, 32(1), 123-142. https://doi.org/10.16986/HUJE.2016018796

Drijvers, P., Kodde-Buitenhuis, H., \& Doorman, M. (2019). Assessing mathematical thinking as part of curriculum reform in the Netherlands. Educational Studies in Mathematics, 102(3), 435-456. https://doi.org/10.1007/s10649-019-09905-7

Gravemeijer, K. (1994). Educational development and developmental research in mathematics education, Journal for Research in Mathematics Education, 25(5), 443471. https://doi.org/10.5951/jresematheduc.25.5.0443

Gravemeijer, K., \& Doorman, M. (1999). Context problems in realistic mathematics education: A calculus course as an example. Educational Studies in Mathematics, 39, 111-129.

Larson, R. (2012). Precalculus, Real Mathematics, Real People (6ed). CENGAGE Learning.

Laurens, T., Batlolona, F.A., Batlolona, J.A., \& Leasa, M. (2018). How does realistic mathematics education (RME) improve students' mathematics cognitive achievement?. EURASIA Journal of Mathematics, Science and Technology Education, 14(2), 569-578. https://doi.org/10.12973/ejmste/76959

Meika, I., Suryadi, D., \& Darhim (2018). Students' errors in solving combinatorics problems observed from the characteristics of RME modeling. IOP Conf. Series: Journal of Physics: Conf. Series 948. https://doi.org/10.1088/1742-6596/948/1/012060 
Stewart, J., Redlin, L., \& Watson, S. (2015). Precalculus Mathematics for Calculus (7ed). CENGAGE Learning.

Sullivan, M. (2013). Precalculus - Enhanced with Graphing Utilities (6ed). Pearson.

Swokowski, E., \& Cole, J. A. (2009) Algebra and trigonometry with analytic geometry (12ed). CENGAGE Learning.

Sumirattana, S., Makanong, A., \& Thipkong, S. (2017). Using realistic mathematics education and the DAPIC problem-solving process to enhance secondary school students' mathematical literacy. Journal of Social Sciences 38, 307-315. http://dx.doi.org/10.1016/j.kjss.2016.06.001

Van den Heuvel-Panhuizen, M. (2003). The didactical use of models in realistic mathematics education: an example from a longitudinal trajectory on percentage. Educational Studies in Mathematics 54, 9-35. https://doi.org/10.1023/b:educ.0000005212.03219.dc

Van den Heuvel-Panhuizen, M., \& Drijvers, P. (2014). Realistic mathematics education. In S. Lerman (Ed.), Encyclopedia of mathematics education. Dordrecht, Heidelberg, New York, London: Springer. 521-525. https://doi.org/10.1007/978-94-007-4978$\underline{8170}$

Wahyudi, Joharman, \& Ngatman (2017). The development of realistic mathematics education (RME) for primary schools' prospective teachers. Advances in Social Science, Education and Humanities Research (ASSEHR), 158, 814-826. https://doi.org/10.2991/ictte-17.2017.83 
Lam Truong Khanh, Duong Huu Tong, Lu Kim Ngan will be applied to their work. Under the terms of this license, no permission is required from the author(s) or publisher for members of the community to copy, distribute, transmit or adapt the article content, providing a proper, prominent and unambiguous attribution to the authors in a manner that makes clear that the materials are being reused under permission of a Creative Commons License. Views, opinions and conclusions expressed in this research article are views, opinions and conclusions of the author(s). Open Access Publishing Group and European Journal of Education Studies shall not be responsible or answerable for any loss, damage or liability caused in relation to/arising out of conflicts of interest, copyright violations and inappropriate or inaccurate use of any kind content related or integrated into the research work. All the published works are meeting the Open Access Publishing requirements and can be freely accessed, shared, modified, distributed and used in educational, commercial and non-commercial purposes under a Creative Commons Attribution 4.0 International License (CC BY 4.0). 